\title{
Impact of a nurse practitioner on patient care in a Canadian emergency department
}

\author{
Ivan P. Steiner, BSc, CScM, MD; ${ }^{*}$ Darren N. Nichols, BMedSc, MD; ${ }^{*}$ Sandra Blitz, MSc; ${ }^{\dagger}$ \\ LloydTapper, RN, BScN, MN; ${ }^{\ddagger}$ Andrew P. Stagg, MD, MSc; ${ }^{\dagger}$ Leneela Sharma, MD; ${ }^{\dagger}$ \\ Carla Policicchio, $\mathrm{RN}, \mathrm{BScN}, \mathrm{MN}^{\ddagger}$
}

\section{ABSTRACT}

Objective: Our objective was to determine whether the addition of a broad-scope nurse practitioner (NP) would improve emergency department (ED) wait times, ED lengths of stay (LOS) and left-without-treatment (LWOT) rates. We hypothesized that the addition of a broad-scope NP during weekday ED shifts would result in shorter patient wait times, reduced LOS and fewer patients leaving the ED without treatment.

Methods: This prospective observational study was conducted in a busy urban free-standing community ED. Intervention shifts, with NP coverage, were compared with control shifts (similar shifts with emergency physicians [EPs] working independently). Primary outcomes included patient wait times, ED LOS and LWOT rates. Patient demographics, triage category, the provider seen, the time to provider and ED LOS were captured using an electronic database.

Results: The addition of an NP was associated with a $12 \%$ increase in patient volume per shift and a 7-minute reduction in mean wait times for low-acuity patients. However, overall patient wait times and ED LOS did not differ between intervention and control shifts. During intervention shifts, EPs saw a smaller proportion of low-acuity patients and there was a trend toward a lower proportion of LWOT patients (11.9\% v. $13.7 \%, p=0.10)$. Conclusion: Adding a broad-scope NP to the ED staff may lower the proportion of patients who leave without treatment, reduce the proportion of low-acuity patients seen by EPs and expedite throughput for a subgroup of less urgent patients. However, it did not reduce overall wait times or ED LOS in this setting.

Keywords: nurse practitioner, emergency care, quality assurance, emergency department, emergency physician

\section{RÉSUMÉ}

Objectif : Nous avons cherché à déterminer si l'ajout d'une infirmière praticienne généraliste améliorerait les temps d'attente, la durée de séjour et le nombre de patients qui quittent
I'urgence sans avoir été vus. Nous avons formulé une hypothèse selon laquelle l'ajout d'une infirmière praticienne généraliste à l'urgence durant les quarts de travail du lundi au vendredi abrégerait les temps d'attente et la durée de séjour à l'urgence et réduirait le nombre de patients qui quittent l'urgence sans avoir été vus.

Méthodes : Nous avons réalisé cette étude d'observation prospective en milieu urbain dans un service d'urgence indépendant et achalandé. Nous avons comparé les quarts de travail au cours desquels une infirmière praticienne était sur place à des quarts "témoins " (quarts similaires, au cours desquels les médecins d'urgence travaillaient sans la collaboration de l'infirmière praticienne). Les principales mesures de résultats incluaient les temps d'attente, la durée de séjour et le nombre de patients quittant l'urgence sans avoir été vus. Une base de données électronique a permis de recueillir les renseignements démographiques suivants : catégorie de triage, professionnel de la santé consulté, temps d'attente et durée du séjour à l'urgence.

Résultats : L'ajout d'une infirmière praticienne a été associé à une augmentation de $12 \%$ du volume de patients par quart et à une réduction de 7 minutes du temps d'attente moyen chez les patients présentant un problème bénin. Toutefois, les temps d'attente et la durée de séjour à l'urgence sont globalement restés les mêmes durant les quarts assurés par une infirmière praticienne et les quarts témoins. Au cours des quarts assurés par une infirmière praticienne, les médecins d'urgence ont vu moins de patients présentant des problèmes bénins, et la proportion de patients quittant l'urgence avant d'avoir été vus a eu tendance à diminuer $(11,9 \%$ c. $13,7 \% ; p=0,10)$.

Conclusion : Ajouter une infirmière praticienne généraliste au personnel de l'urgence pourrait réduire la proportion de patients qui quittent I'urgence sans avoir été vus et la proportion de patients présentant des problèmes bénins qui sont vus par les médecins d'urgence, en plus d'accélérer le traitement d'une catégorie de cas moins urgents. Toutefois, dans l'ensemble, cet ajout n'a abrégé ni les temps d'attente, ni la durée de séjour à l'urgence dans ce contexte.

From the *Departments of Family Medicine and Emergency Medicine, University of Alberta, Edmonton, Alta., the †Department of Emergency Medicine, University of Alberta, Edmonton, Alta., and the $¥$ Northeast Community Health Centre, Alberta Health Services, Edmonton, Alta.

Submitted May 12, 2007; Revised Feb. 12, 2008; Accepted Jan. 7, 2009

This article has been peer reviewed.

CJEM 2009;11(3):207-14 


\section{INTRODUCTION}

Nurse practitioners (NPs) have been a part of Canadian health care since the 1970s; however, their role in emergency departments (EDs) remains unclear. ${ }^{1-3} \mathrm{~A}$ recent Canadian study suggested that autonomous patient care provided by an NP was not equivalent to care provided by an emergency physician (EP). ${ }^{4}$ The authors also proposed a scope of practice for ED NPs and recommended a collaborative, rather than independent, practice role.

A recent systematic review of the impact of emergency NPs on cost, care quality, patient satisfaction and wait times contains no Canadian data. Information describing the function of ED NPs is available from sources in the United States, the United Kingdom and Australia but, in these settings, health care delivery differs in design, staffing and approach. In the United States, EPs are responsible for the provision of emergency care, but the for-profit system may influence results. ${ }^{5}$ Emergency departments in the United Kingdom and Australia are frequently staffed by midlevel postgraduate trainees rather than EPs. ${ }^{6,7}$ Therefore, data from these settings are not necessarily generalizable to Canada.

In 2003, the Alberta Ministry of Health provided a grant for the introduction of an NP into an Edmonton ED. ${ }^{4}$ The assumptions underlying this grant were that the addition of an NP to the ED multidisciplinary team would create an emergency service delivery model that would optimize the use of EPs and provide an alternative to EP care for appropriate clinical presentations. ${ }^{4}$ The goal of our prospective observational study was to determine the impact of the new NP on key ED operational outcomes. ${ }^{8}$ We hypothesized that for the shifts during which an NP was present, patient wait times (door-to-evaluation by physician or NP) and ED length of stay (LOS) would be shorter, and that fewer patients would leave without treatment, particularly patients triaged as categories 1-3 of the Canadian ED Triage and Acuity Scale (CTAS). ${ }^{8}$

\section{METHODS}

\section{Patients and setting}

The Northeast Community Health Centre (NECHC) is a community-based primary health care facility with an attached 24-hour free-standing ED that, in 2005, provided emergency care to 46600 patients. The NECHC ED is similar to a small urban community or regional $\mathrm{ED}$, but differs from an urgent care centre, as patients from all CTAS categories are treated, and the ED is staffed by full-time EPs. Table 1 shows that $42.4 \%$ of NECHC patients fell into the CTAS $1-3$ high-acuity categories in $2005 .^{8}$ This distribution is similar to many community hospitals, except for a relative paucity of CTAS-1 patients. In 2005, 2303 (4.9\%) NECHC patients required emergency medical service (EMS) transfer to acute care institutions and 1199 $(2.6 \%)$ visits resulted in admission to hospital.

At the time of this study, the NECHC patient assessment area included 13 stretchers, 2 resuscitation bays, a multipurpose cast room, and a room and curtained area with 4 chairs each. Despite managing patients from all CTAS categories, the NECHC does not have in-patient beds, admitting physicians or on-site consultant support. Patients requiring admission to hospital or diagnostic imaging beyond plain radiography and basic ultrasonography are referred to acute care hospitals. In light of these limitations, the ED accepts EMS patients only after screening by the EP and the charge nurse. Physicians working at the NECHC also provide care at a tertiary care university-affiliated trauma centre and are remunerated based on an alternative, non-fee for service payment plan.

\section{Intervention}

In October 2005, an NP was introduced to the ED during a selection of weekday daytime shifts. In our health region, NPs have a 37.5 hour workweek limit, in which 32 hours are devoted to clinical practice and 5.5 hours to research or administration. ${ }^{4}$ Consequently, our NP's clinical work consisted of 3.5 eight-hour daytime shifts per week, starting at 7:30 or 10:00 am.

Qualifications and selection of NPs have been described in detail elsewhere. ${ }^{4}$ The NP's clinical collaborative scope

\begin{tabular}{|c|c|}
\hline CTAS category & No. (\%) of patients, $n=46599$ \\
\hline 1 & $20 \quad(0.04)$ \\
\hline 2 & 1549 \\
\hline 3 & 18187 (39.0) \\
\hline 4 & 24119 (51.8) \\
\hline 5 & 2724 \\
\hline $1-3$ & 19756 (42.4) \\
\hline $4-5$ & $26843(57.6)$ \\
\hline
\end{tabular}


of practice is similar to that of residents, with the EP retaining ultimate decision-making authority. Nurse practitioners also provide health promotion and counselling in primary care domains. Through a collaborative model, EPs can delegate specific discretionary tasks such as direct patient care, discharge planning and follow-up arrangements to an NP. The NP's autonomous scope of practice is limited to specific CTAS-4 and -5 patient categories. ${ }^{5}$

\section{Patient allocation}

Patient allocation to the NP was not random. During the 7:30 am shifts, the NP first managed patients in the follow-up ED-intravenous (IV) clinic, unless the EP required urgent help. For the 10:00 am shift the NP shift did not include IV clinic patients. All other patients were seen directly by the NP based on a "next to be seen" CTAS priority, or as requested by the EP.

Every NP shift during the study period, excluding those with study investigators or uninitiated physicians, was included and considered an "intervention" shift. Control shifts, defined as shifts covered only by an EP, were identified and matched as closely as possible based on date, start time and day of week. All patients registered in the ED during control and intervention shifts were eligible for analysis. The same cohort of EPs worked control and intervention shifts and all shifts were weekday morning shifts.

During intervention shifts, NPs saw patients within the autonomous or within the collaborative scope of practice. Patients who were seen first by the EP, and then had specific tasks delegated to the NP, were recorded as patients attended to by the EP. The resulting delegated services provided by the NP in such scenarios will be reported elsewhere.

\section{Data collection}

The NECHC ED information system database yielded information about patient encounters by the care provider(s), patient demographics, triage category, registration time, time seen and disposition time. Incomplete information was omitted. Each NP-patient encounter was categorized as collaborative or autonomous. Data was gathered prospectively from Feb. 1 to Jul. 31, $2006 .{ }^{4}$

\section{Outcomes}

The primary outcomes were patient wait times from triage to EP or NP assessment stratified by CTAS level, the overall ED LOS (arrival to departure) and the number and proportion of patients who left without treatment (LWOT) stratified by CTAS level.

\section{Data analysis}

The primary comparison was between intervention and control shifts. Data were aggregated for each CTAS category and analyzed based on prospective acuity strata, and overall. When appropriate, medians and interquartile ranges were calculated. The statistical significance of observed differences in interval outcomes was assessed using a Wilcoxon 2-sample test. The significance of observed differences in categorical outcomes was determined using $\chi^{2}$ analysis. Mixed modelling methods were used to account for the correlated nature of the data. These models assumed that data collected within each shift were correlated and that the NP effect would be nested within that level. All models included the CTAS level as a covariate, dichotomized into level $1-3$ and level 4-5. A mixed linear regression model was fit to determine whether there was an effect on wait times and LOS during NP shifts. Similarly, a generalized estimating equation logistic model was fit to determine if there was an effect on the number of patients who left without treatment during an NP shift. Results of statistical tests were deemed significant at the 0.05 level.

\section{Ethics}

Health review ethics board evaluation was requested and the need for review was waved by the panel. Identifying information was not collected and all data are reported in aggregate.

\section{RESULTS}

During the study period, the NP worked 68 day shifts with 21 eligible EPs. Data from these shifts were compared with 51 day shifts in which the same physicians worked independently. Of the 4025 patients registered, 319 were excluded because of incomplete data and 468 left without treatment, leaving 3238 patient visits for analysis (Fig. 1). Of these, 1314 visits occurred during control shifts and 1924 during intervention shifts. Table 2 shows that the median number of patients seen on intervention shifts $(\mathrm{EP}+\mathrm{NP})$ was 28 , compared with 25 on control shifts (EP alone), reflecting a $12 \%$ increase in patient throughput per shift $(p<0.001)$. Table 2 shows no 
significant differences in overall median wait times or in ED LOS. For all triage categories, LWOT rates were slightly lower during intervention shifts. The overall LWOT rate was $11.9 \%$ (259 of 2183) during intervention shifts versus $13.7 \%$ (209 of 1523) on control shifts; a trend that was not statistically significant.

Figure 1 and Table 3 show that the NP saw 599 patients; 220 (36.7\%) collaboratively and 379 (63.3\%) autonomously, a median of 9 patients per 8 -hour shift. The wait times and LOS were lower in the autonomous CTAS 4-5 categories than for other cohorts (Table 2, Table 4). Of note, 305 follow-up outpatient IV therapy visits (CTAS 4) are included in the NP autonomous scope of practice group.

Figure 2, Figure 3 and Figure 4 illustrate performance distributions for key study outcomes. Figure 5 shows that EPs managed a larger proportion of CTAS 1-3 patients when the NP was present.

\section{DISCUSSION}

This study examined the effect of adding an NP to a community hospital ED during weekday shifts. To our knowledge this is the first published Canadian data describing the impact of an NP on ED operational outcomes. Our findings suggest the addition of an NP results in a $12 \%$ increase in patient throughput volume (limited to lower acuity patients), but no significant improvement in wait times, ED LOS or LWOT rates. It is important to note that the NP scope of practice in the study setting differs from the traditional, autonomous, fast-track approach used in other jurisdictions. ${ }^{4,-11}$ Our model, as described by Drummond, ${ }^{3}$ promotes NP involvement in the care of all CTAS category patients.

\section{Nurse practitioners in the setting of ED overcrowding}

Emergency department overcrowding is a crisis in Canadian EDs. It causes diagnostic and treatment delays, increases the number of patients who leave without treatment and adds to patient morbidity and mortality. ${ }^{12-16}$ In the province of Alberta, ED patients have the lowest level of satisfaction in the Canadian health care system, a phenomenon closely linked to ED wait times. ${ }^{17}$ Therefore, an intervention that shortens wait times and LOS would be expected to improve patient care, reduce LWOT rates and enhance patient satisfaction. The role of the NP has been advocated as such an intervention.

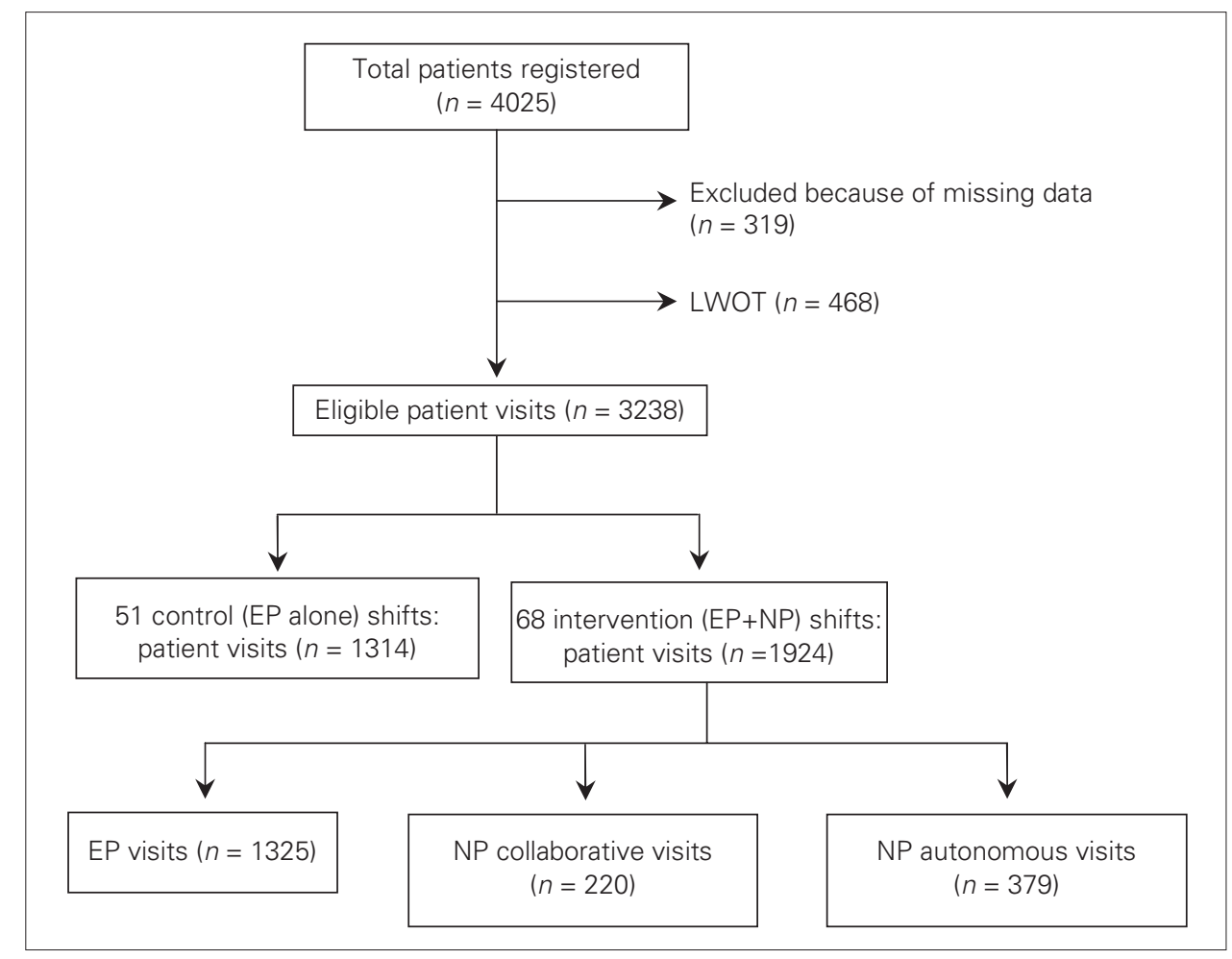

Fig. 1. Study flow sheet. EP = emergency physician; LWOT = left without treatment; $\mathrm{NP}=$ nurse practitioner. 
In our setting, the addition of an NP was associated with a 7 -minute reduction in wait times for nonurgent patients $(p=\mathrm{NS})$, but no improvement in overall wait times or LOS, particularly for CTAS $1-3$ patients. There are several potential reasons for these findings. First, most patients with higher acuity require an ED stretcher, but many stretchers are blocked by patients awaiting transfer, admission, diagnostic imaging or

\begin{tabular}{|c|c|c|c|}
\hline \multirow[b]{2}{*}{$\begin{array}{l}\text { Outcome, } \\
\text { CTAS level }\end{array}$} & \multicolumn{2}{|c|}{ Median (IQR)* } & \multirow[b]{2}{*}{$p$ value } \\
\hline & Control, EP alone & $\begin{array}{c}\text { Intervention, } \\
E P+N P\end{array}$ & \\
\hline \multicolumn{4}{|l|}{ Patients/shift } \\
\hline 1 & $1 \quad(1-1)$ & $1 \quad(1-1)$ & \\
\hline 2 & $1 \quad(1-2)$ & $1 \quad(1-2)$ & \\
\hline 3 & $9 \quad(7-10)$ & $9 \quad(8-11)$ & \\
\hline 4 & 14 (11-18) & $17 \quad(13-20)$ & \\
\hline 5 & $1 \quad(1-1)$ & $3 \quad(2-5)$ & \\
\hline All patients & $25 \quad(21-28)$ & $28 \quad(26-31)$ & $<0.001 \dagger$ \\
\hline \multicolumn{4}{|l|}{ Wait time, min } \\
\hline $1-3$ & 61 (34-103) & 63 (37-98) & \\
\hline $4-5$ & 67 (35-108) & $60 \quad(32-99)$ & \\
\hline All patients & 65 (35-105) & 61 (34-99) & $0.62 \ddagger$ \\
\hline \multicolumn{4}{|l|}{ ED LOS, min } \\
\hline $1-3$ & $154(106-234)$ & $168(111-244)$ & \\
\hline $4-5$ & $103(64-154)$ & 103 (67-159) & \\
\hline All patients & $123(76-184)$ & $125 \quad(78-192)$ & $0.13 \neq$ \\
\hline \multicolumn{4}{|c|}{ LWOT, no. (\%) of patients } \\
\hline 1 & $(0.0)$ & $(0.0)$ & \\
\hline 2 & $(2.1)$ & $0 / 45$ & \\
\hline 3 & $66 / 519 \quad(12.7)$ & $67 / 708 \quad(9.5)$ & \\
\hline 4 & $121 / 862 \quad(14.0)$ & 166/1303 (12.7) & \\
\hline 5 & $21 / 93 \quad(22.6)$ & 26/126 (20.6) & \\
\hline Total & 209/1523 (13.7) & 259/2183 (11.9) & $0.10 \S$ \\
\hline \multicolumn{4}{|c|}{$\begin{array}{l}\text { CTAS = Canadian Emergency Department Triage and Acuity Scale; ED = emergency } \\
\text { department; EP = emergency physician; IQR = interquartile range; LOS = length of } \\
\text { stay; LWOT = left without treatment; NP = nurse practitioner. } \\
\text { *Unless otherwise indicated. } \\
\text { tWilcoxon sign-rank test. } \\
\text { tMixed linear regression model, with CTAS as a covariate. } \\
\text { §Generalized estimating equation logistic regression model, with CTAS as a covariate. }\end{array}$} \\
\hline
\end{tabular}

consultation. The addition of an NP would not be expected to overcome these other "system" barriers. Second, all CTAS 1-3 patients seen by the NP required $\mathrm{EP}$ review, and in some cases, the physician may have been a limiting factor.

LWOT rates in Canadian EDs range from $2.4 \%$ to $10.2 \%{ }^{18-20}$ In our study, the $11.9 \%$ LWOT rate during NP intervention shifts, although lower than the $13.7 \%$ seen during control shifts, was not statistically significant $(p=0.10)$. Patients triaged at CTAS 3 accounted for $12.7 \%$ of the LWOT from control and $9.5 \%$ intervention shifts, and these rates were lower than the $27 \%$ CTAS-3 LWOT rate cited elsewhere. ${ }^{19}$ Both the overall LWOT levels and CTAS-3 proportions are a cause for concern, because these patients often require acute assessment and treatment. Other studies have reported that $60 \%$ of LWOT patients seek subsequent medical care, $73 \%$ have a change in their ongoing treatment and $4.1 \%$ are admitted to hospital after their first return visit (or within 2 wk)..$^{12,14,19}$ A US study found that $11 \%$ of LWOT patients were admitted to hospital within 1 week. ${ }^{15}$

\section{Nurse practitioners and the international context}

Data from UK and Australian fast-track or free-standing units $^{21-23}$ show that wait times and LOS for NP care were lower or comparable to resident level care, but direct comparisons with EPs are not available. Our NP managed an average of 9 autonomous and collaborative patients per 8-hour shift, a number in keeping with the 1-2 autonomous patients per hour described in other countries. This suggests that, despite a different scope of practice, our NP had an efficiency comparable to other settings. ${ }^{5}$ Wait times and LOS for CTAS 4-5 patients seen by the NP were shorter when in the autonomous rather than collaborative mode (Table 4), but this efficiency did not translate into shorter wait times or LOS for sicker patients, suggesting again that

\begin{tabular}{|c|c|c|c|c|c|}
\hline \multirow[b]{3}{*}{ CTAS level } & \multicolumn{5}{|c|}{ Median no. of patients per shift (IQR) } \\
\hline & \multirow{2}{*}{$\begin{array}{c}\text { Control } \\
\text { EP alone }\end{array}$} & \multicolumn{4}{|c|}{ Intervention } \\
\hline & & EP & NP autonomous & NP collaborative & NP all patients \\
\hline $1-3$ & $10(8-11)$ & $9(7-10)$ & NA & $2(1-3)$ & $2(1-3)$ \\
\hline $4-5$ & $15(12-20)$ & $11(7-13)$ & $6(4-7)$ & $2(1-3)$ & $7(6-9)$ \\
\hline Total & $25(21-28)$ & $20(17-22)$ & $6(4-7)$ & $4(2-5)$ & $9(7-10)$ \\
\hline
\end{tabular}


access block for higher acuity stretcher patients was a greater determinant than the presence or absence of an NP.

\section{Interpretation}

The interpretation of our results will undoubtedly vary with the reader's perspective. The fact that EPs saw

\begin{tabular}{|c|c|c|}
\hline \multirow{2}{*}{$\begin{array}{l}\text { Outcome, } \\
\text { CTAS level }\end{array}$} & \multicolumn{2}{|c|}{ Median (IOR) time, min } \\
\hline & Collaborative & Autonomous \\
\hline \multicolumn{3}{|l|}{ Wait times } \\
\hline $1-3$ & $69(41-99)$ & NA \\
\hline $4-5$ & 63 (22-108) & $39(20-71)$ \\
\hline All patients & 65 (32-106) & $39(20-71)$ \\
\hline \multicolumn{3}{|l|}{ ED LOS } \\
\hline $1-3$ & $207(156-281)$ & NA \\
\hline $4-5$ & $153(96-202)$ & $77(49-110)$ \\
\hline All patients & $174(108-222)$ & $77(49-110)$ \\
\hline
\end{tabular}

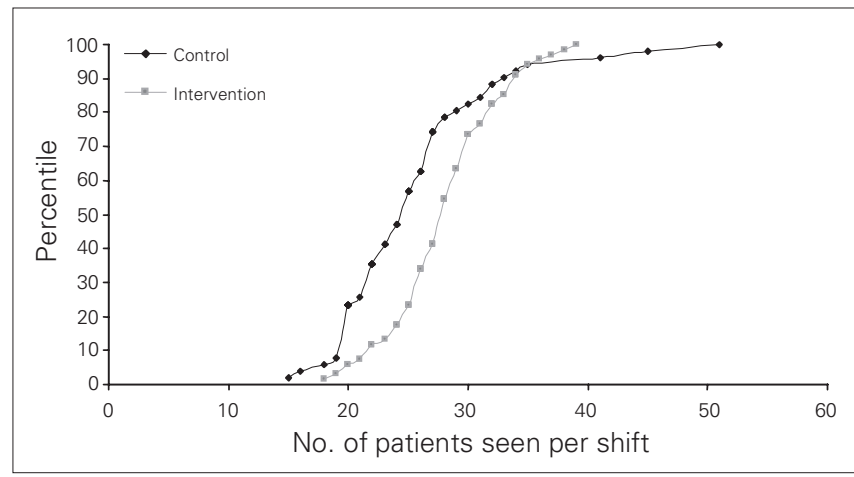

Fig. 2. Patients seen per shift during control and intervention shifts.

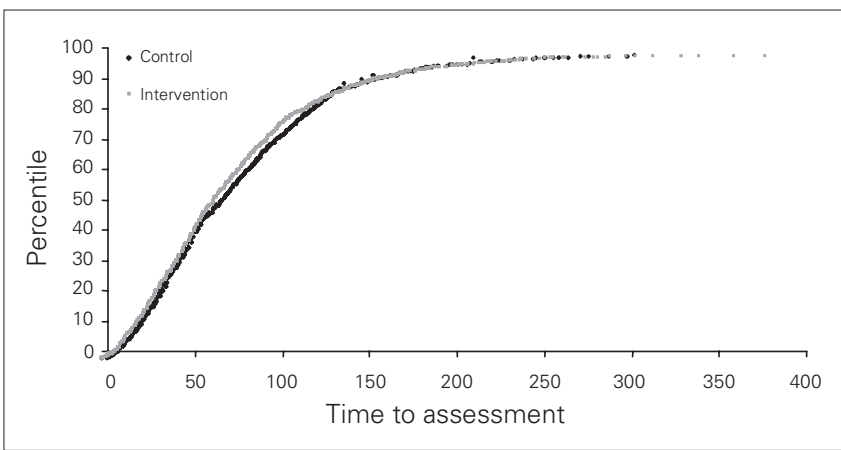

Fig. 3. Emergency department wait times during control and intervention shifts. more patients per shift ( 25 v. 9) with higher acuity, and that there were no significant differences for wait times, ED LOS or LWOT rates during NP intervention shifts, could lead to the argument that the most efficient approach is EPs working alone. In contrast, it could be argued that $12 \%$ more patients ( 28 v. 25$)$ were seen on NP intervention shifts (although it is intuitive that 2 caregivers will manage more patients than 1), and that the presence of an NP enabled EPs to care for fewer CTAS 4-5 patients and dedicate a greater proportion of their time to higher acuity patients or more complex problems.

\section{Limitations}

The study design was not ideal, in that our program development grant provided limited resources that precluded a randomized trial approach. Although we made efforts to adjust our data for CTAS acuity, unmeasured differences in other baseline variables could

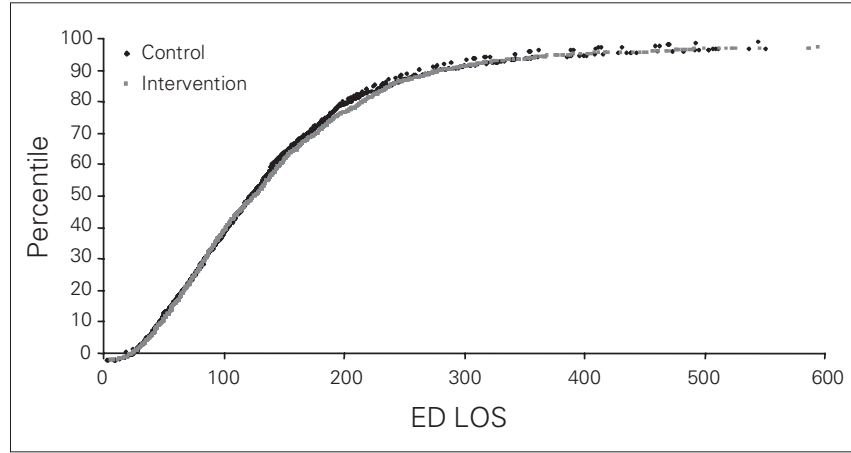

Fig. 4. Emergency department lengths of stay (LOS) during control and intervention shifts.

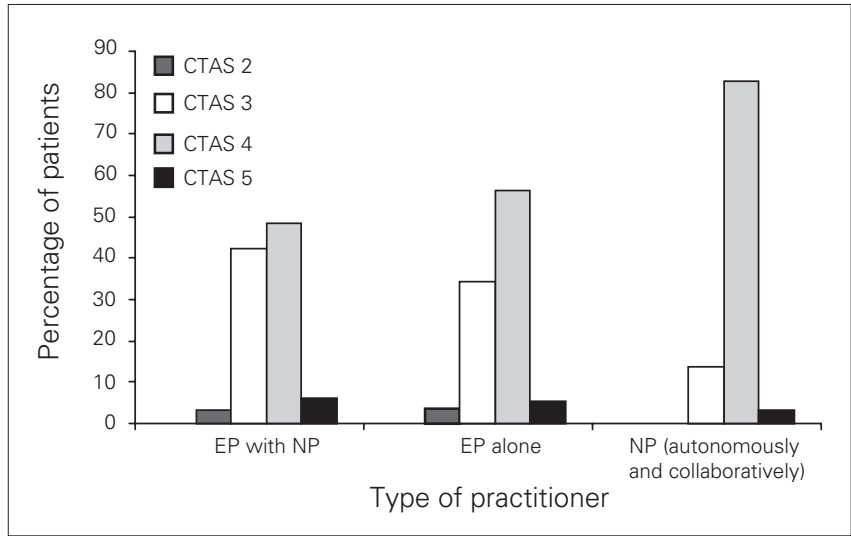

Fig. 5. Proportion of patients by Canadian Emergency Department Triage and Acuity Scale (CTAS) category and type of practitioner. EP = emergency physician; NP = nurse practitioner. Note: CTAS 1 count is 1 for each group and is $0 \%$. 
have influenced key outcomes. Missing data and the exclusion of observations from shifts worked by the study investigators may have introduced bias. The external generalizability of our results is limited by the fact that our data reflect the practice of one NP working at one site. In addition, many autonomous NP patients were IV antibiotic return visits, a situation that may not exist in other settings. Although our NP had a 4-month "run-in" period before the onset of data collection, we would expect that NP competence and efficiency would increase over time, and that the long-term impact of an ED NP may differ from that estimated in this study. Our study looked only at wait times, ED LOS and LWOT rates, and did not consider other important quality outcomes that might be improved by an NP, such as patient education, provider communication, patient satisfaction and provider satisfaction. A formal cost-effectiveness analysis was not incorporated in this study. Finally, although we found some NP-related benefit (i.e., a $12 \%$ increase in shift volume), we did not attempt to compare this with the potential benefit of alternate staffing models such as adding a physician assistant or an extra EP.

Emergency physician satisfaction data and a qualitative analysis based on a physician focus group will be reported subsequently, and future research should address other quality outcomes discussed above. Determination of cost-effectiveness would be ideal before widespread funding of ED NP initiatives in other Canadian settings.

\section{CONCLUSION}

Adding a broad-scope NP to the ED staff mix may lower the proportion of patients who leave without treatment, reduce the proportion of low-acuity patients seen by EPs, and expedite throughput for a subgroup of less urgent patients, however it did not reduce overall wait times or ED LOS in this setting.

Acknowledgements: The authors thank Dr. Brian Rowe from the Department of Emergency Medicine, University of Alberta, and Dr. Janet Raboud from the Department of Dalla Lana School of Public Health, University of Toronto for their critical review and recommendations; Jackie Brace-Peter from Capital Health; and Tamara Thiessen from Alberta Health Services, for assistance in data retrieval.

Competing interests: The Alberta Health and Wellness Medical Services Delivery Innovation Fund (MSDIF) paid Drs. Steiner and Sharma for developing the program and Drs.
Steiner and Stagg for assessing the program, Mr. Tapper is a Capital Health employee, Ms. Policicchio is an Alberta Health Services (Edmonton area) Site Director.

Funding: The MSDIF grant to develop and asses the program was provided by the provincial Ministry of Health in Alberta.

\section{REFERENCES}

1. Worster A, Sardo A, Thrasher C. Understanding the role of nurse practitioners in Canada. Can J Rural Med 2005;10:89-94.

2. Thrasher C, Purc-Stephenson RJ. Integrating nurse practitioners into Canadian emergency departments: a qualitative study of barriers and recommendations. CJEM 2007;9: 275-81.

3. Drummond A. Nurse practitioners in Canadian emergency departments: an idea worthy of attention or diverting our attention? CJEM 2007;9:297-9.

4. Steiner IP, Blitz S, Nichols DN, et al. Introducing a nurse practitioner into an urban Canadian emergency department. CJEM 2008;10:355-63.

5. Carter AJE, Chochinov AH. A systematic review of the impact of nurse practitioners on cost, quality of care, satisfaction and wait times in the emergency department. CJEM 2007;9:286-95.

6. Sakr M, Kendall R, Angus J. Care of minor injuries by emergency nurse practitioners or junior doctors: a randomised controlled trial. Emerg Med 7 2003;20:158-63.

7. Kumar NL, Black D, McClellan K. Daytime presentations to a metropolitan ophthalmic emergency department. Clin Experiment Ophthalmol 2005;33:586-92.

8. Beveridge R. The Canadian Triage and Acuity Scale: a new and critical element in health care reform. Canadian Association of Emergency Physicians. J Emerg Med 1998;16:507-11.

9. Brebner JA, Ruddick-Bracken H, Norman JN, et al. The nurse practitioner: management of minor trauma. Accid Emerg Nurs 1996;4:43-6.

10. Considine J, Martin R, Smit D, et al. Defining the scope of practice of the emergency nurse practitioner role in a metropolitan emergency department. Int J Nurs Pract 2006;12:205-13.

11. Dolan B, Dale J, Morely V. Nurse practitioners: the role in A\&E and primary care. Nurs Stand 1997;11:33-8.

12. Derlet RW, Richards J. Overcrowding in the nation's emergency departments: complex causes and disturbing effects. Ann Emerg Med 2000;35:63-8.

13. Trzeciak S, Rivers EP. Emergency department overcrowding in the United States: an emerging treat to patient safety and public health. Emerg Med J 2003;20:402-5.

14. Rowe BH, Bond S, Ospina MB, et al. Frequency, determinants, 
and impact of overcrowding in emergency departments in Canada: a national survey of emergency department directors [Technology report no. 67.3]. Ottawa (ON): Canadian Agency for Drugs and Technologies in Health; 2006.

15. Asplin BR, Magid DJ, Rhodes KV, et al. A conceptual model of emergency department crowding. Ann Emerg Med 2003; 42:173-80.

16. Holroyd BR, Bullard MJ, Latoszek K, et al. Impact of a triage liaison physician on emergency department overcrowding and throughput: a randomized controlled trial. Acad Emerg Med 2007;14:702-8.

17. Health Quality Council of Alberta. Emergency Department Patient Experience Survey. The Council; 2008. Available: www.hqca.ca/assets/pdf/News\%20Releases/HQCA_ED_Sur vey/HQCA_ED_survey_technical_report.pdf (accessed 2009 Apr 2).

18. Fernandes CM, Price A, Christenson JM. Does reduced length of stay decrease the number of emergency department patients who leave without seeing a physician? 7 Emerg Med 1997;15:397-9.

19. Rowe BH, Channan P, Bullard M, et al. Characteristics of patients who leave emergency departments without being seen. Acad Emerg Med 2006;13:848-52.

20. Jack LKA, Thomson J, Nemeth L. Does the emergency department of a Canadian tertiary-care university-affiliated hospital meet the time goals set by the Canadian Triage and Acuity Scale? ISRJEM 2008;89:8-14. Available: http://isrjem .org/March08_NEMETH-DOES\%20A\%20CANADIAN .postprod.pdf (accessed 2009 Mar 27).

21. Rogers T, Ross N, Spooner D. Evaluation of a see and treat pilot study introduced to an emergency department. Accid Emerg Nurs 2004;12:24-7.

22. Considine J, Martin R, Smit D, et al. Emergency nurse practitioner care and emergency department patient flow: casecontrol study. Emerg Med Australas 2006;18:385-90.

23. Jennings N, O'Reilly G, Lee G, et al. Evaluating outcomes of the emergency nurse practitioner role in a major urban emergency department, Melbourne, Australia. J Clin Nurs 2008; 17:1044-50.

Correspondence to: Dr. Ivan Steiner, 205 College Plaza, 8215 - 112 St., Edmonton AB T6G 2C8; ivan.steiner@ualberta.ca

\section{Change of address}

We require 6 to 8 weeks' notice to ensure uninterrupted service. Please send your current mailing label, new address and the effective date of change to:

\section{Canadian Association of Emergency Physicians}

104-1785 Alta Vista Dr. Ottawa ON K1G 3Y6

613 523-3343

fax $613523-0190$

cjem@caep.ca

\section{Changement d'adresse}

II nous faut de 6 à 8 semaines d'avis afin de vous assurer une livraison ininterrompue. Veuillez faire parvenir votre étiquette d'adresse actuelle, votre nouvelle adresse et la date de la prise d'effet du changement, à l'attention du

\section{Association canadienne des médecins d'urgence}

104-1785, prom. Alta Vista

Ottawa ON K1G 3Y6

613 523-3343

fax 613 523-0190

cjem@caep.ca 